\title{
Financial Literacy of Graduate High School Students
}

\author{
Tsakiridou Helen*, Seitanidis Ilias \\ Faculty of Education, University of Western Macedonia, Florina, Greece \\ *Corresponding author: etsakir@uowm.gr \\ Received December 16, 2018; Revised January 22, 2019; Accepted March 11, 2019
}

\begin{abstract}
The purpose of this study is to investigate the level of financial literacy of high school students, especially graduate students of general high school. In a constantly evolving world people need to manage a variety of daily financial statements. The requirements deriving from the financial environment makes it necessary to have basic financial knowledge. The transmission of such knowledge through teaching financial lessons and performing respective educational programs, as part of basic and especially secondary education, aimed at financial literacy of students. The aim of the financial literacy is for the students to be able to address adequately the financial challenges while improving their standard of living at present and in the future.
\end{abstract}

Keywords: financial literacy, financial fields, general high school students

Cite This Article: Tsakiridou Helen, and Seitanidis Ilias, "Financial Literacy of Graduate High School Students." American Journal of Educational Research, vol. 7, no. 3 (2019): 232-236. doi: 10.12691/education-7-3-7.

\section{The Term and the Importance of Financial Literacy}

The term of financial literacy has a number of definitions from several researchers. Amongst others, financial literacy is the knowledge and understanding of financial concepts, risks and skills, motivation and confidence of individuals to apply this knowledge and understanding to make effective decisions through a wide range of financial frameworks, with final aiming at broader participation of society in economic life and improve personal financial prosperity [1].

Moreover, it is the combination of knowledge, skills, awareness, attitudes and behavior, which is necessary for proper financial decisions leading to the ultimate aim of achieving financial prosperity. A financial literate person has a basic understanding of financial concepts and the ability to apply numerical skills in the management of financial statements [2].

In addition, it is the ability of individuals to use their knowledge and skills to effectively manage their financial resources with a view to economic and financial security during their lifetime. The financial literacy refers to an ongoing adequacy situation making any person capable of effectively responding to changing personal and financial conditions [3].

Finally, it is the ability to use these concepts with the basic objective of effective management of financial resources with the ultimate goal of financial well-being of individuals in the course of their life [4]. The financial literacy involves skills and confidence for the effective application or use of knowledge related to personal financial concepts and products leading to personal financial behaviors, which in turn have an impact on the financial well-being of people [5].

It should be noted that individuals are considered financial literate, when they are able to demonstrate that they can use in practice the knowledge they have gained. Obtaining financial standing is indicated when the individual improves the level of financial literacy while simultaneously evolving financially on a personal level [6].

\section{Skills and Knowledge of Financial Literate Graduate High School Students}

Graduate students of high school should take responsibility for personal financial matters. They must be able to explain how people behave responsibly to achieve economic prosperity and to analyze how the financial responsibility is different between people with dependent relatives and those without protected family members, when given a statement discussing ethical issues related to the various financial decisions at a personal level [7].

Moreover, it is necessary to have a brief knowledge of basic consumer protection laws. Graduate students should be able to take into account the consumer protection laws and the safeguards they provide, seek written and electronic sources with updated information on consumer rights and given a failing state, they should be able to draw up a letter of protest, including the issue on the documents and the necessary contact information in order to take concrete measures to tackle [7].

What is more, a graduate student of high school should be able to set measurable short-, medium- and long-term financial goals. They should also be able to calculate the costs required in order to achieve a long-term target, 
follow the systematic decision making, achieve a longterm target, study the changes in inflation as a financial decision-maker, study imposing taxes as a determinant of financial decisions and give examples of how decisions are taken [7].

Graduate students must be able to calculate and consider the risks and costs that exist in starting a business and by outlining the main points of a business plan, they should analyze how economic, social, cultural and political conditions can affect income and career prospects [7].

It is of high importance to identify the factors that affect net earnings. As a result, graduate students should be able to explain the effect of net income on the amount of withholding of work allowances, transfer the information from a tax return and interest bank document to the income tax application form of the respective institution deposits, fill in a tax refund application and examine the benefits of the available savings programs in order to increase its individual income in the future [7].

Graduate students should develop a plan for the financial costs and savings. They must be able to explain how the budget can be used in order to manage costs and to establish financial goals, as well as distinguish the money management behaviors that lead to the accumulation of wealth and analyze how changes in personal financial circumstances can affect a personal budget [7].

Additionally, they should evaluate alternative investment opportunities. The graduate student of high school should be able to discuss the possible types of business risks, comparing the risks and returns of different types of investments. Moreover, they should be able to calculate the return on investment, based on different investment amounts, timetables and rates of return, describing the advantages of a diversified investment portfolio. They should also identify appropriate types of investments in order to achieve liquidity objectives, income and development and identify the suitability of Luce types of investments in order to harvest money for the achievement of four-year studies, marriage, starting a business, housing market advance payment or car and retirement and using systematic decisions on the selection of an investment generally [7].

Regarding the explanation of the impact of taxes on investment performance, the graduate students of high school should be able to compare the returns of taxable investments in particular categories of investment tax. They should be able to compare the advantages of traditional retirement in personal account, and describe the benefits provided in pension saving which are subsidized by the employer [7].

Finally, the graduate students of high school should investigate investor protection by regulators of financial markets or they must be able to explain investor protection by federal and state regulators [7].

\section{Financial Literacy Surveys in Secondary School Students}

A series of researches have attempted to provide questions concerning the level of financial literacy of high school students and to identify the possible correlations that this level displays considering the diverse demographic and personal data of the students. In the context of these researches, the search for new methods of the educational process was aimed at improving the students' financial literacy level [8]. Studying the level of financial literacy of secondary school students and seeking educational tools to improve it, has been a major concern not only for the educational community, but also for the governments of the world at a global level [9].

A common denominator of the results of surveys for secondary school students in all countries, is their low level of financial literacy, both in developed countries such as the USA, Canada, Italy, Austria, and England and in developing countries such as South Korea and Hungary [8].

The Jump\$tart Coalition for Personal Financial Literacy was set up in December 1995 to encourage enrichment of teaching curricula and to ensure that students acquire the ability of personal financial management during secondary education. The organization states in its mission statement that it seeks to investigate and assess the level of financial literacy of juvenile minors and to disseminate the usefulness of key fields of financial knowledge through developing and promoting the teaching of personal financial management [10].

In the USA $(1997,2000,2002,2004,2006,2008)$ the level of financial literacy of secondary school students was measured using a questionnaire created by the organization Jump\$tart Coalition for Personal Financial Literacy, which also conducted the surveys [8]. The questionnaire included 50 multiple choice questions, 20 of which looked at the students' demographic and personal data, on which the Jump\$tart Coalition for Personal Financial Literacy [3] depends on the individual and independent age. The remaining 31 examined the students' understanding of four main financial fields: 1) Income, 2) Programming and Management of Money, 3) Credit and Debt, 4) Savings and Investments. The available time for students to complete the questionnaires was 60 minutes. Sample of all surveys were students of the third grade of the Lyceum of Public Schools in the United States. The questionnaire questions were adapted to their age [8].

The results did not indicate a correlation between gender and the level of financial literacy of sample students. In the first survey of 1997 there was the highest percentage of students' financial literacy. The average of the correct answers of the students to the total of questions was only $57.3 \%$. Subsequent surveys showed equally low results, with the lowest rate occurring in the last chronological survey of 2008. The average of the correct answers of the students to the total of questions was $48.3 \%$. The organization's forecasts that by 2008 the average of the correct answers of the students to the total of questions from $58.3 \%$ would reach at least $60 \%$, proved to be wrong. On the contrary, there was a decrease of 10 percentage points [10].

The first two surveys in 1997 and 2000 showed that family students with annual income ranging from $40,000 \$$ to $79,999 \$$ had better performance than family students with an annual income of more than $80,000 \$$ per year. In the 2006 survey, there were different outcomes about the correlation between the sample household 
income and the level of financial literacy. Students with an annual family income of less than 20,000\$ scored an average of the right answers to $48.5 \%$ of the questions, as opposed to $55.6 \%$ of the average students' average annual family income of more than 80,000 \$ per year [11].

In the second survey of the organization in 2000, the sample was 723 students in the third grade of the Lyceum from all over the United States. There was also a correlation between the level of financial programming and the students' work history. Students scored slightly better in the main financial income field, which was found to be positively linked to students who stated they had employment during the school year [10].

In 2003, in South Korea and under the supervision of Jump \$tart Coalition for Personal Financial, a survey was conducted to measure the level of financial literacy of secondary school students in the country. The sample of the survey was students of the first and second grades of the public high schools in the country. The result of the survey showed that sample students had a low level of financial literacy. In particular, the sample of students did not achieve more than $50 \%$ of the correct answers in any of the financial fields of the questions [8].

Hungary is characterized as an economically weak country in Europe, with a low birth rate index and a low level of financial literacy of its citizens. In 2006 the Hungarian Central Bank developed a program to develop the level of financial literacy of secondary school students. The survey was conducted by 1000 students aged 14-17. The instrument of measurement was the house interviews conducted in September 2006 by the Gallup Organization Hungary. The main result of the survey was that the majority of sample students are not interested in financial issues and financial services, although they consider them important [12].

\section{Method}

The objective of the survey is to measure the level of financial literacy of high school students of General Lyceum students in all questions and in each basic field of financial knowledge. The results examined were based on the demographic and personal characteristics of the sample. The key areas identify financial knowledge where the highest and lowest student performance occurs. The basic fields of financial knowledge are 1) Income, 2) Programming and Money Management, 3) Credit and Debt and 4) Savings and Investments.

Research tool for measuring the level of financial literacy is the questionnaire of the Jump\$tart Coalition for Personal Financial Literacy, which was created and used by the organization in all its researches. Financial literacy questions correspond to the four basic financial fields which have been expanded by the organization, but for historical continuity, it continues to use the initial categorization.

Moreover, the Greek social reality and the legal framework of the Greek state obliged us to make necessary changes to the Jump\$tart Coalition for Personal Financial Literacy standard questionnaire when translating, composing and compiling the new questionnaire of this survey. The customized questionnaire of the survey contains 40 multiple choice questions, the first 10 of which examine pupil's demographic and personal characteristics and the other 30 ones contain the exploratory part of the survey. The available time for students to complete the questionnaires is 60 minutes.

It is of high importance to highlight that the students had received the same level of education, there was a common background for secondary school students and that the time frame for the completion of the questionnaire was forty minutes, in which the students were under objective and impartial surveillance.

For the purposes of the survey, a random sample of 300 students from the third grade of general high schools in Thessaloniki (57\% girls and $43 \%$ boys) was taken. Specifically, $76.7 \%$ of students in the sample had Greek origin and $23.3 \%$ had non-Greek origin. The $75.7 \%$ of the sample students intended to continue their education at University or Higher Technological Educational Institution, 7.7\% in Vocational Training Institute, 9\% had other plans for training and education, $5.3 \%$ did not know his educational plans and $2.3 \%$ did not intend to further education.

In demographic factor of students parents' education, $40.7 \%$ of students replied that one of their parents is a graduate of a University, $29.7 \%$ stated that one of their parents graduated from high school, $17.3 \%$ said that one of their parents attended a school after the high school, $10 \%$ answered that none of their parents graduated from high school while $2.3 \%$ replied that they did not know the level of their parents' education.

Regarding the family income in the previous year, $36.3 \%$ commented that it was less than $15.000 €, 27.7 \%$ commented that it was from $15000 €$ to $24.999 €, 10.7 \%$ replied that it was between $25.000 €$ and $39.999 €, 2.7 \%$ replied that it was more than $40.000 €$ and $22.7 \%$ said that they did not know.

Moreover, $47.7 \%$ of the sample students answered that they had a bank account, $10.3 \%$ said that they had a credit card and $23 \%$ replied that they were using a debit card.

According to the work history, $2.3 \%$ of the sample students responded that they had worked full-time in the summer and part-time during the school period, 9.7\% stated that they had worked full-time and $9 \%$ of them admitted having worked part-time in the summer and parttime during the school year. $21.3 \%$ replied that they had worked part-time in the summer with no employment during the school year, and $57.7 \%$ replied that they had never worked officially.

The data gathered was processed with the SPSS statistical packet. Frequency tables were calculated to find the average of the correct answers of the sample students in the set of questions, each question and each field of financial knowledge where the questionnaire questions were grouped. A frequency table was also created for the demographic and personal characteristics of the sample. T-test statistical tests and analysis of variance with one factor were applied. When the Scheffe test showed no statistically significant difference between two groups, the post-hoc LSD control was alternatively applied. In the event of a statistically significant difference in fluctuations, the Games-Howell post-hoc audit was implemented. 


\section{Presentation of Results}

The average of correct answers of sample of students to the total of questionnaire questions was $39.6 \%$. Both boys and girls had almost the same performance, indicating that the average of correct answers was not affected by the gender of the students $(t=-0.50, d f=256.836, p=0.62)$.

Greek and foreign students had on average the same performance and the average of correct answers of students in the sample did not seem to be influenced by the country of origin of students $(\mathrm{t}=0.57$, $\mathrm{df}=298$, $\mathrm{p}=0.57)$.

Students had nearly the same performance regardless of whether they intended to continue their studies or not. Some of them may decide to follow academic studies, a Higher Technological Educational Institution or a Vocational Training Institute. Some others may have other training plans, while some of them may not intend to follow any further education. Finally, some students have not decided yet the next step after their graduation from high school $(\mathrm{F} 4,295=2.07, \mathrm{p}=0.09)$.

Students had averagely the same performance, regardless of whether one of their parents did not attend high school, was a high school graduate, was a graduate of another faculty, was a University graduate or a graduate of Higher Technological Educational Institution, or if students were not aware of their parents' education. $(\mathrm{F}=1.14, \mathrm{df}=4.295, \mathrm{p}=0.34)$.

The performance of students varied according to family income $(\mathrm{F}=6.49$, df $=4.295, \mathrm{p}<0.001)$. There was a notable difference in the performance of students who had a family income of less than $15.000 €(42.1 \%)$ or between $15.000 €$ and $24.999 €(42.8 \%)$ with surprisingly high performances compared to the group of students who replied that they did not know their family income (34.4\%) and the group of students whose parents had income from $25.000 €$ to $34.999 €(34.4 \%)$.

Students with a bank account and students with no bank account had on average the same performance $(\mathrm{t}=-0.84$, $\mathrm{df}=298, \mathrm{p}=0.40)$, as did students who owned a credit card and those who did not own one $(\mathrm{t}=0.08$, df $=298$, $\mathrm{p}=0.94)$. Similar are the findings in students who owned a debit card and in those who did not own one $(\mathrm{t}=0.91$, $\mathrm{df}=298, \mathrm{p}=0.37$ ).

However, the performance of students differs depending on the students' work history $(\mathrm{F} 4,295=4.9, \mathrm{p}=0.001)$. There was a difference in performance for students who had never worked officially reaching the highest score $(41.6 \%)$ and the group declared that had worked part-time during the school year and during the summer (32.3\%).

In the first financial field of Income the students correctly answered on average to three of the seven questions (44.4\%). The performance of students differs depending on family income $(\mathrm{F}=4.4$, df $=4.295$, $\mathrm{p}=0.002)$. The performance of students who replied that had a family income less than $15.000 €(46.1 \%)$ and a family income from $15.000 €$ to $24.999 €(48.9 \%)$ being the highest.

In the second financial field of Money Planning and Management, the students correctly answered less than two of the four questions (44.2\%). Students' performance varies according to the family income $(\mathrm{F}=3.34$, $\mathrm{df}=4.295, \mathrm{p}=0.010)$. Specifically, the performance of students claimed that they had a family income of less than $15.000 €(47.9 \%)$ is higher than the performance of students who said that they had a family income from $25.000 €$ to $39.999 €(32.8 \%)$.

In the third financial field of Spending and Debit, the students correctly answered on average to two of the five questions $(38.7 \%)$. Student performance depending on family income $(F=3.65$, df $=4.295, p=0.006)$. Students who replied that they had a family income of between $15,000 €$ and $24,999 €(42.5 \%)$, achieved a higher performance than the students who stated that they did not know their family income (34.2\%).

Student's performance in Spending and Debt questions varies according to a second demographic factor, the student's work history $(\mathrm{F}=3.24$, $\mathrm{df}=4.295, \mathrm{p}=0.010)$. There is a difference in performance in favor of students who had never worked officially $(40.3 \%)$ and to those who replied that they had worked part-time in the summer and did not have employment during the school term $(40.9 \%)$, compared to the performances of students who had worked full-time in the summer and did not have a job during the school year (31.4\%) and those who responded that they had part-time work during the summer and during the school period $(30.6 \%)$.

In the fourth financial field of Saving and Investing, the students correctly answered about three of the eight questions $(34.3 \%)$. The performance of students differs depending on the work history of the students $(\mathrm{F}=3.30$, $\mathrm{df}=4.295, \mathrm{p}=0.010)$. There was a difference in performance in favor of students who had never worked officially (36.1\%) and those who replied that they had worked part-time in the summer and did not have employment during the school term (34.6\%).

\section{Conclusions}

The main conclusion of the survey is that the level of financial literacy of high school students in the general high school of the sample is low in agreement with the corresponding low rates of high school students in other countries where similar surveys were conducted $[8,10]$.

The gender and the origin of the students did not affect the student performance in the sample. The educational plans after high school, the level of parents' education and the possession of bank account, debit or credit card, did not affect the performance of the students in the sample either.

In contrast, family income affects the level of financial literacy of sample students with the amount of income being inversely proportional to the financial knowledge. Students with a family income of less than $15,000 €$ show a better level of financial literacy than students who do not know their family income. Also, sample students with a family income of between $15,000 €$ and $24,999 €$ have a better level of financial literacy than students who do not know their family income and then students with a family income of between $25,000 €$ and $34,999 €$. This result may be due to the fact that lower-income students are more likely to face unfavorable financial and real-life financial situations in personal and family level. As a consequence, they have acquired indirectly or have recourse directly to the search for appropriate information in order to understand these financial statements and their treatment. 
Moreover, the work history affects the performance of the students in the sample, perhaps in the opposite direction from what someone would suppose. Although students who have stated that they have worked part-time both during the summer months and during the school year are more likely to have come into more direct contact with financial issues, they showed lower levels of financial literacy than students who have never worked officially. The lack of time and the lack of interest in monitoring and understanding deep-seated financial issues of sample students are perhaps potential causes of the influence of work history on the level of financial programming as depicted in this research.

Finally, the low rate of financial planning is not positively influenced by the financial courses attended by sample students in their school curriculum. The noninfluence of economic courses on improving students' financial literacy may be due to the non-core position of these courses in the curriculum, the content of the lessons themselves and the way in which the thematic modules are taught by the teachers. This fact is speculated by the number of wrong answers of sample students to questions that are not difficult and do not need to recall pre-existing knowledge from short or long-term memory, but simple understanding of these questions is required [13].

Students in the sample did not achieve an average of answers of more than $50 \%$ in any of the four fields of financial knowledge, which confirms the low level of financial literacy of general high school students in the sample of this survey. Higher student performance was observed in the financial field of Income and the lowest in the financial field of Saving and Investing, both in the present survey and in all surveys of Jump\$tart Coalition for Personal Financial Literacy which conducted in the USA [11].

This result is likely to be due to the financial situations empirically experienced by sample students and to the type of financial information they derive daily from their environment, given that in the period of economic crisis, we are in the forefront of discussions and news on issues related to the reduction of income and adapting most households to the new circumstances. Thus, the majority of the population has disappeared from financial affairs investment and savings [14]. Furthermore, the standardized and accumulated knowledge that students are expected to receive through the high school is likely to play a significant negative role in the low level of financial literacy of sample students.

One possible cause of the low rate of financial literacy of students in the sample is perhaps the failure to give proper weight to the basic financial knowledge of the
Greek education system as a whole. Financial education programs that exist in Greek reality seem to be incomplete, obsolete and unable to meet the needs of modern everyday life. The above position results from the presentation, in the framework of the present study, of the economic courses of secondary education in Greece [13].

Finally, it may be interesting to investigate the causes of the graduate students in the sample of this research presenting a lower level of financial literacy, compared to the low level of financial literacy of high school students in other countries. Other areas that could also be investigated are the reasons why the characteristics of family income and work history of students interact differently at the level of financial literacy between students in the sample of this research and high school students in other countries.

\section{References}

[1] PISA, Financial Literacy Framework. Paris, 2012.

[2] Atkinson, A., Messy, F.A., Assessing financial literacy in 12 countries: an OECD/INFE international pilot exercise. Journal of Pension Economics \& Finance, 2011, 10.4: 657-665.

[3] JumpStart Coalition. National Standards in K-12 Personal Finance Education. 2007. Washington, DC.

[4] Hung, A., Parker, A. M., Yoong, J., Defining and measuring financial literacy. 2009. RAND Corporation.

[5] Huston, S. J., Measuring financial literacy. Journal of Consumer Affairs, 2010, 44.2: 296-316.

[6] Moore, D. L., Survey of financial literacy in Washington State: Knowledge, behavior, attitudes, and experiences. 2003, Washington State Department of Financial Institutions,

[7] Bannister, R., Dlabay, L., Hampton, V., Heckman, P., Kerbel, C., Lang, N., \& Ward, J. National Standards in K-12 Personal Finance Education. Jump\$tart Coalition for Personal Financial Literacy, 2007, Washington, DC.

[8] OECD, Improving financial literacy: Analysis of issues and policies. 2005, OECD Publishing.

[9] PACFL, United States Department of the Treasury Office of Financial Education. President's Advisory Council on Financial Literacy, 2008 Annual Report to the President. 2008, USA

[10] Jump\$tart Coalition for Personal Financial Literacy. The financial literacy of young American adults. 2008, Washington, DC.

[11] Mandell, L., Financial literacy of high school students. In: Handbook of consumer finance research. Springer, New York, NY, 2008. p. 163-183.

[12] Habschick, M., et al., Survey of financial literacy schemes in the EU27. VT Markt/2006/26H-Final Report, Hamburg, 2007.

[13] Makridou-Bousiou, D., Economic knowledge in secondary Education (a valuation for high school students in public high schools Of Macedonia). Unpublished doctoral dissertation, University of Macedonia, 1992, Thessaloniki, Greece.

[14] National Council on Economic Education (NCEE), Survey of the States: Economic and personal finance in our nation's schools, 2011. 